\title{
O DIÁLOGO: ARGUMENTAÇÃO PRÁTICA E CONDIÇÕES DE AFETIVIDADE
}

\author{
Jorge Campos da Costa* \\ Jonas Rodrigues Saraiva** \\ Pontifícia Universidade Católica do Rio Grande do Sul \\ Faculdade de Letras \\ Porto Alegre, RS, Brasil
}

\begin{abstract}
Resumo: O presente ensaio é uma tentativa de abordagem interdisciplinar sobre o diálogo argumentativo prático em sua dimensão lógica e afetiva, na perspectiva de um desenho teórico em que razão e emoção coexistem numa relação entre racionalidade natural e racionalidade formal. As hipóteses assumidas são as de que o diálogo representa o locus classicus da argumentação prática em sua estrutura linguístico-cognitivo-comunicativa; que a racionalidade stricto sensu, representada pela dedutibilidade, é objeto de uma disciplina a saber a Lógica Clássica; e que tal disciplina pode ser incluída numa perspectiva de racionalidade lato sensu, objeto de uma visão interdisciplinar em que coexistem Lógica, Linguística, Psicologia Cognitiva, Teoria da Comunicação entre outras. Central para a investigação é a identificação de inferência em suas variadas dimensões dentro das mencionadas áreas, o jogo da linguagem das emoções e suas conexões com as condições de verdade, na perspectiva da validade e aceitabilidade de argumentos.
\end{abstract}

Palavras-chave: Diálogo. Inferência. Emoção. Argumento.

"Mais valem dúvidas articuladas do que certezas obscuras".

Russell

1 INTRODUÇÃO

O diálogo pode ser assumido como a mais básica das formas de interatividade social. Ainda que sob as mais diversas maneiras de se apresentar, é razoável supor-se, abdutivamente, que o diálogo tenha suas raízes de base inata, dada sua presença em qualquer sociedade humana, independente da forma de cultura, desde as mais antigas, gregas, hindus, chinesas, etc., até as sofisticadas conexões tecnológicas das redes sociais. As versões clássicas, especialmente na cultura grega, valorizaram o diálogo como meio mais democrático, justo e transparente de se produzir conhecimento compartilhado. Nele predomina o caráter argumentativo, pelo qual, no debate teórico, uma pessoa persuade ou é persuadida de que certas opiniões são verdadeiras ou falsas. Os famosos diálogos de Platão, como o Crátilo e o Sofista, entre dezenas de outros, são exemplos de argumentação sobre importantes teses filosóficas.

\footnotetext{
* Professor do Programa de Pós-graduação em Letras. E-mail: jcampos@pucrs.br.

** Doutorando do Programa de Pós-graduação em Letras. Email: jonasrsaraiva@hotmail.com.
} 
O trabalho de Aristóteles (2010) sobre as relações entre os argumentos analíticos, dialéticos ou retóricos trouxe importante contribuição para uma abordagem da racionalidade humana em suas dimensões lógico-matemáticas e em seu caráter de debate natural e prático. Na primeira dimensão (lógico-matemática, na perspectiva silogística - Organon, 2010), abstrai-se uma forma lógica que garante a validade do argumento sem se recorrer ao seu conteúdo; na segunda, trata-se de avaliar o uso da argumentação em sua realidade ampla, ou seja, numa proposição instanciada por expressões de conteúdo. Assim como, no primeiro caso, aspectos específicos e individuais (propriedades semânticas) são desconsiderados, no segundo, inúmeros ingredientes (tais como relações de sentido, hiponímias, metáforas, sinonímias, etc.) fazem parte do processo argumentativo. Um deles é o contexto das condições de emocionalidade envolvidas numa situação de persuasão (ELSTER, 1999), sedução, interesse político, etc. Tais condições, digamos, de adequação afetiva, representam a forma como as emoções, mais propriamente a linguagem das emoções, impacta sobre a racionalidade discursiva em sentido amplo ${ }^{1}$.

De modo mais geral, razão e emoção interagem num processo de argumentação prática, entendida como o uso do argumento, embora a emoção seja abstraída (prescindida) numa perspectiva de argumentação restrita, entendida como aquela que se encontra reduzida a sua forma lógica. A ideia fundamental é que a argumentação prática pressupõe uma forma de racionalidade ampla - que deve ser entendida na interface semântico-pragmática ou, de outra maneira, a que é construída na relação argumento formal e uso do argumento -, incluindo a modelagem formal de validade - e não se opondo a ela. O problema é que, historicamente, tem havido uma rejeição - conforme Perelman (1996), Ducrot (apud MOURA, 1998) e Walton (diálogo), por exemplo - da dedutibilidade para abordagens da linguagem natural, em nome de sua impropriedade, quando o que se deveria assumir é a sua limitação para isso. Os fundamentos da racionalidade prática devem, portanto, incluir os de racionalidade restrita, para uma interface adequada com linguagem, cognição e comunicação. Em tal interface, os processos inferenciais são considerados em suas propriedades multiformes, desde a dedução clássica até as inferências pragmáticas canceláveis tipo implicaturas, pressuposições, acarretamentos, implícitos conversacionais, implicações contextuais, etc. (COSTA, 2009).

Nesse roteiro, podem-se considerar as inferências conectadas com aspectos emocionais como articuladas aos argumentos práticos (em uso), nos quais o impacto das emoções cumpre funções de adequação para que o dito e o inferido sejam interpretados de maneira relevante (compatível com a noção de Sperber e Wilson (1986)). Dado esse contexto temático, seguem-se três seções que culminam com as considerações finais: a primeira, sobre a Lógica na interface com a linguagem natural; a segunda, sobre a emoção na interface com a linguagem natural, e a terceira, sobre argumento-validade na interface com argumento-plausibilidade.

\footnotetext{
${ }^{1} \mathrm{O}$ que se disse deve ser entendido como uma proposta de valor exploratório, levantando hipóteses relevantes para a discussão científica sobre o assunto. Do pathos de Aristóteles ao movimento revolucionário de Damásio (1994) sobre o papel da emoção nas tomadas de decisão, tal propriedade vem sendo reconhecida como partícipe de quaisquer outras relações dialógicas.
} 
A Lógica Clássica - entendida como o cálculo de predicados de primeira ordem com identidade, incluindo a lógica proposicional (MENDELSON, 1987; LEMMON, 1987) -, em seus fundamentos dedutivos, é a disciplina que aborda, formalmente, a validade ou não de argumentos, nos quais, de premissas verdadeiras, não se possa chegar a conclusões falsas. A dedução é o processo de raciocínio em que a inferência conclusiva é necessária, monotônica (que mantém sua função lógica mesmo com a introdução de outras premissas), em contraste com outras, não necessárias, não monotônicas ou canceláveis. Assim, "Todo mamífero é um ser vivo" e "Todo ser vivo morre" levam à necessária conclusão de que "Todo mamífero morre". Isso é assim, porque há uma forma lógica que torna o argumento válido em qualquer ocorrência. Todo A é B, todo B é C, portanto, e necessariamente, todo A é C.

Já um argumento como "Se isto é uma flor, então é uma rosa; é uma rosa, então é uma flor" pode ser considerado aceitável ainda que não válido dedutivamente, caso em que $\mathrm{P} \rightarrow \mathrm{Q}, \mathrm{Q}$ não levam necessariamente a $\mathrm{P}$, embora, sob o ponto de vista semântico, seja perfeitamente aceitável. Ocorre que, em contrapartida ao argumento lógicodedutivo, com sua forma lógica, o argumento em linguagem natural envolve algo que se poderia chamar forma do conteúdo, no caso uma hiponímia em que o termo 'rosa' é um hipônimo de 'flor', e 'flor', um hiperônimo de 'rosa'. Se o argumento fosse formatado em outra ordem lexical, como "Se isto é uma rosa, então é uma flor; é uma flor, portanto é uma rosa", seria inválido e inaceitável.

De maneira similar, a linguagem de emoções também se estrutura semanticamente, o que pode determinar questões problemáticas para a argumentação natural, ou prática. Por exemplo, 'amar', 'estar apaixonado' e 'gostar' mantêm relações como as de intensidade e de profundidade. 'Amar' é assumido como mais profundo que 'apaixonar-se', e este é assumido como mais profundo que 'gostar'2. De modo que um argumento do tipo dialógico

[1]

A - Se João está apaixonado por Maria, então vai casar com ela.

B - De fato, está apaixonado, mas não a ama. Não casará, portanto.

parece ser aceitável, ainda que a conclusão seja negada e o argumento seja inválido; de duas premissas verdadeiras, a conclusão esperável era que iria casar com ela. A forma lógica poderia ser $\mathrm{P} \rightarrow \mathrm{Q},(\mathrm{P} \wedge \neg \mathrm{R})$, portanto, $\mathrm{Q}$, válida. $\mathrm{O}$ contexto da argumentação, no caso, via forma do conteúdo, envolve conhecimento enciclopédico - entendido como interface entre conhecimento de mundo e conhecimento linguístico. Apaixonar-se é menos razão do que amar para casar-se, ou seja, a paixão não é entendida como suficiente, embora seja entendida como necessária. Da mesma maneira, dizer que "João casará com Maria, porque gosta dela" parece implicar que sim, embora 'gostar dela' seja necessário, mas não seja suficiente para casar.

\footnotetext{
${ }^{2}$ Toma-se por base, aqui, a noção escalas de significado de Horn (1972).
} 
O aspecto interessante aqui é o fato de que a forma lógica dos argumentos pode ser desenhada para argumentos dedutivos estritamente formais, monotônicos, portanto, mas não deixa de acontecer que possam ser usados no nível dos raciocínios práticos, não monotônicos, por exemplo, envolvidos com aspectos heteromórficos (não homogêneos), como o significado na interface semântico-pragmática. Isso é semelhante a dizer que o argumento, em seu uso, é objeto complexo e demanda abordagem interdisciplinar, o que significa que o conjunto de inferências naturais tem, como subconjunto, as lógicas em sentido estrito, numa abordagem que vai além da questão da validade puramente formal - tal interpretação pode ser justificada por uma compreensão via interfaces; a [interface] comunicativo-social pode ser assumida como contendo a formal no sentido de que a forma lógica como tal é uma abstração de $n$ ocorrências. Assume-se, neste caso, um compromisso com um tipo de racionalidade ampla, ainda tratável - evidentemente não se pode radicalizar no sentido de que o passo na direção da lógica informal possa ser argumento cético contra a racionalidade. Tal racionalidade, numa interface lógico-cognitivo-comunicativa, certamente é constituída de inferências de interfaces distintas, sem que a visão disciplinar da Lógica Clássica seja posta em jogo. Pelo contrário, de maneira análoga, trata-se da construção de interfaces sintáticosemântico-pragmáticas, onde a razão formal (operação lógico-dedutiva), a cognitiva (operação mental) e a social (operação comunicativa) se aproximam em solidariedade de perspectivas.

Nesse caminho, ainda que as emoções tenham representado, historicamente, ameaças à racionalidade no uso dos argumentos, elas sempre estiveram juntas ${ }^{3}$. Não por outra razão, Aristóteles tratou de diferenciar a inferência analítica da dialética e da retórica, sendo a primeira livre de contexto e as duas últimas formas de uso dos argumentos. A Retórica, então, pode ser entendida como disciplina que inclui uma teoria das emoções (pathos) na perspectiva aristotélica.

\section{A EMOÇÃO NA INTERFACE COM A LINGUAGEM NATURAL}

Há três perspectivas para a interface linguagem-emoção ${ }^{4}$ : a primeira é o fato de que, dado o uso da linguagem, como no caso de um diálogo, a interatividade entre os locutores está dentro de um contexto de condições de verdade e de condições afetivas; a segunda é que as emoções estão gramaticalizadas, suas propriedades podem ser expressas nos diversos níveis: fonológicos, morfológicos, lexicais, sintáticos, semânticos e pragmáticos; a terceira é que a emoção está na interface entre a forma e o conteúdo, numa função de intenções persuasiva, política, amorosa, etc. presentes no argumento prático. Ilustramos, no exemplo a seguir, as perspectivas de construir um contexto afetivo-emocional, usando, para isso, o diálogo espontâneo:

\footnotetext{
3 As origens desse pensamento já foram identificadas por Aristóteles através da noção de pathos (ARISTÓTELES, 2012).

${ }^{4}$ Trata-se de defender a validade da suposição operatória para fins de relacionamento entre razão e emoção.
} 
[2]

A - Oi, querida! Tudo bem?

B - Oi, minha amiga, tudo bem.

A - Já estava com saudade.

$\mathrm{B}-\mathrm{Eu}$, também.

A - E aquele gato do teu irmão Marcos, ainda solteiro?

B - Sim. És candidata?

A - Se ele está só, e me quiser, é claro, sim.

B - Mas ele é genioso, tu sabes.

A - Sim, mas me dou bem com toda a família.

B - Que bom, então, serás minha cunhadinha.

A - Já ganhei o dia, mas tenho que ir pra aula. Até depois.

B - Até depois, "cunhadinha".

No contexto do diálogo, as condições de validade e de aceitabilidade da verdade, ou veracidade, coexistem com as condições de afetividade. Estas últimas podem ser caracterizadas como espontâneas e amigáveis. Ou seja, tais condições afetivas são adequadas ou relevantes para o contexto informativo em que as amigas aceitam como veraz que Marcos está solteiro e que "A" aceitaria namorar Marcos. Há consenso de que ele é genioso, mas "A" mantém sua intenção. Os argumentos "Se ele está solteiro e me quer, então eu aceito" e "Ele está, portanto, aceito" têm sua validade semânticopragmática também aceita.

Condições de afetividade, em princípio, representam um contexto em que as condições de veracidade ${ }^{5}$ - ditas e inferidas - são otimizadas (fortalecidas). Suponhamos que, de maneira só falsamente amigável, "A" estivesse ironizando. A ironia não parece ser adequada a este diálogo. Alguém que o observasse, como não protagonista, não o entenderia como adequado ao que foi dito e inferido. Não há traços explícitos nem inferíveis de ironia ${ }^{6}$. Já a propriedade de amigabilidade pode ser identificada em vários aspectos. A forma como se cumprimentam, a forma carinhosa como se despedem, etc. Mesmo um diálogo outro, de caráter científico, envolve tais condições. Por exemplo, o entusiasmo dos interlocutores que compartilham certas verdades científicas que ambos defendem. Ou, ao contrário, o clima de agressividade em que eles competem. Diálogos otimizados são, portanto, os que combinam veracidade e afetividade de maneira adequada. Nada impede que as condições de afetividade mudem, no decorrer do diálogo, a ponto de os interlocutores se afastarem, porque não há condições, diriam eles. Que condições são essas? As de afetividade adequada.

\footnotetext{
${ }^{5}$ No nível da lógica stricto sensu, estudam-se as condições de verdade - propriedade de uma proposição ser verdadeira ou falsa. Na lógica lato sensu (uso dos argumentos), não podemos afirmar verdades senão no sentido de condições de veracidade ou condições de aceitabilidade da verdade - propriedade de uma proposição em uso ser plausível ou não. No uso do argumento, as condições de afetividade manifestam-se como adequação ou não desse uso, ou como fatores de força do argumento - os sofistas, por exemplo, já eram acusados de emocionar as pessoas para convencê-las. As condições de afetividade estão em relação com as condições de veracidade e de verdade no uso dos argumentos.

${ }^{6}$ Ressalte-se o fato de que ser irônico ou não é uma suposição dependente do contexto da situação.
} 
Evidentemente que, mesmo entre inimigos, o diálogo é possível se as referidas condições minimamente funcionam. Veja-se o caso de Israel versus Palestina. O diálogo parece fracassar. Há condições de veracidade problemáticas, não há consenso sobre elas. Há condições de afetividade problemáticas, não há a mínima tolerância.

Quanto à segunda maneira de interfaciar emoção e linguagem, trata-se de constituir o que se pode chamar de "emoções verbais". Cada nível de interface interna entre as subpartes tem formas de expressar emoções e afetividade em geral. Ilustremos tal fenômeno em cada nível, usando o diálogo [2] em pauta ${ }^{7}$ :

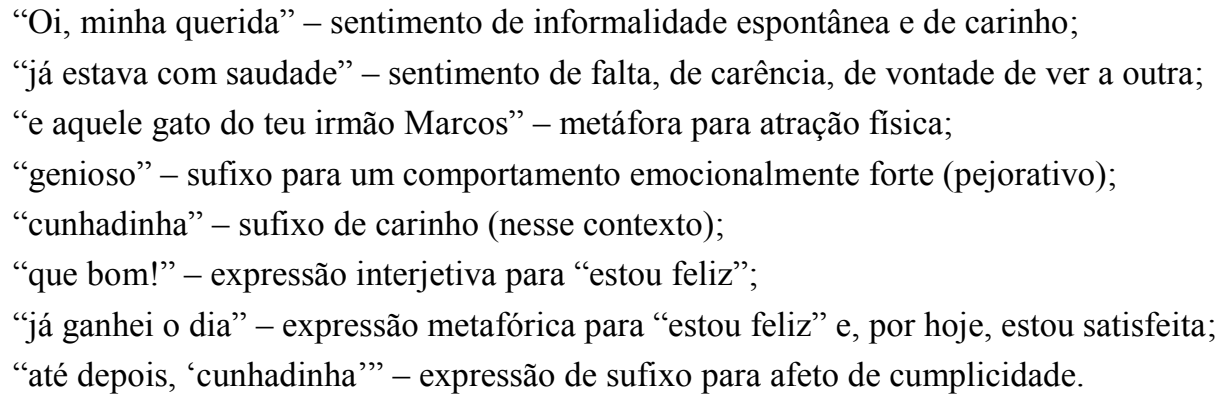

A terceira forma de tratar a linguagem na interface com as emoções é reconhecêlas como indiscutíveis ingredientes retóricos a serviço de intenções diversas. Essa propriedade é, no final das contas, a que mais preocupou os gregos antigos (especialmente Platão e Aristóteles), dado o efeito de se deslocar a questão da verdade para a dos efeitos retórico-emocionais. Convencer, mesmo sem o amparo da verdade, é a denúncia de Platão para os sofistas (PLATÃO apud HEIDEGGER, 2012). Hoje, pela intensificação dos processos dialógicos no mundo digital, aparece, mais claramente, o poder da retórica em qualquer área do conhecimento, especialmente a que busca interativamente a emoção, principalmente a da arte e a da política. A poesia, desde Homero e Hesíodo, é o lugar clássico das formas ricas retoricamente. A emoção na retórica do herói grego e sua revolta é seu ponto central. A poesia lírica de Vinícius de Moraes e sua insinuação retórica de sensualidade é um outro inspirado exemplo. Consideremos alguns efeitos retóricos como ilustração ${ }^{8}$ :

[3]

"A lógica nos leva de A para B; a imaginação, de A para qualquer lugar."

(Einstein)

\begin{abstract}
"Essa mulher é um mundo, é uma cadela, mas na moldura de uma cama, nunca mulher nenhuma foi tão bela."

(Vinícius de Moraes)
\end{abstract}

\footnotetext{
${ }^{7}$ Não custa repetir que não se trata da análise das emoções em si mesmas, mas da análise da linguagem das emoções e da forma como condições de afetividade interagem no interior do diálogo.

${ }^{8}$ Permitem-se ao leitor suas próprias interpretações, pois não temos a pretensão de oferecer respostas prontas para as relações forma-sentido, como estímulo para futuras investigações.
} 
"O pior casamento é o que dá certo."

(Millor Fernandes)

"Yes we can."

(Obama)

"Saio da vida para entrar na história."

(Getúlio Vargas)

"O poeta é um fingidor, finge tão completamente que chega a fingir que é dor a dor que deveras sente."

(Fernando Pessoa)

De fato, a retórica pode ser construída como operações da forma sobre o conteúdo. "Eu simpatizo contigo", "Eu gosto de ti", "Eu estou apaixonado por ti”, "Eu te amo", "Eu te amo totalmente demais", enquanto atos de fala (AUSTIN, 1965; SEARLE, 1979), envolvem graus de emoção em que a forma gera uma inferência adicional de expressividade amorosa. $\mathrm{O}$ resultado é que a função poética, nas palavras de Jakobson (1987), ocorre quando a linguagem volta-se para si mesma. Isso quer dizer que o significado da proposição é enriquecido por formas pragmáticas capazes de despertar, no nível poético, uma espécie de emoção estética, assim como a retórica de um pavilhão político é capaz de incitar as massas à violência, capaz da brutalidade de uma guerra, como o que resultou da emoção e do sentimento nazistas. O contexto da afetividade e da emoção estão, portanto, em todas as ocorrências de uso da linguagem.

O que ocorre é que há um contexto emocional em que um enunciado é interpretado, há uma forma de gramaticalização em que as expressões linguísticas incorporam a linguagem das emoções, e, finalmente, há uma expressividade retórica com potencial para propósitos do tipo persuasão, sedução, protestos, etc. Uma das propriedades mais interessantes da retórica das emoções é como o raciocínio lógico em sentido amplo é capaz de interagir com o papel da função argumentativa ligado às emoções.

\section{EMOÇÕES NO ARGUMENTO NATURAL NA INTERFACE COM O ARGUMENTO LÓGICO}

O argumento lógico-dedutivo é uma forma abstrata para uma estrutura racional stricto sensu, em que as premissas, uma vez verdadeiras, não devem levar a conclusões falsas. A dedução é, em princípio, um conjunto de regras normativo-descritivas em que os exemplos são meras ilustrações para uma disciplina formal. O argumento lógiconatural é uma estrutura racional lato sensu, em que, além de formas, considera-se o conteúdo dos enunciados que fazem o papel do que é dito, e de inferências necessárias ou canceláveis.

Os exemplos [1-3] fazem parte do contexto pragmático em que os usos dos argumentos complexos são os objetos de descrição e explicação, dinamicamente 
assumidos, numa perspectiva não normativa, em que as formas de racionalidade criativa são possíveis. São modelados [esses exemplos] numa área interdisciplinar, simulando inferências múltiplas numa racionalidade complexa. Nessa perspectiva, o contexto das condições de afetividade, de sentimentos e de emoções ${ }^{9}$, enquanto linguagem natural, podem ser relevantemente investigados como de potencial interesse tanto para áreas de lógica informal (lato sensu, conforme já mencionado), como para experimentos na neurociência. Em última instância, numa interface linguístico-lógico-cognitivocomunicativa, o papel das emoções e de suas relações com formas de racionalidade humana pode ser mais bem explicado. O diálogo (estrutura/processo do diálogo, nesse caso) continua sendo nosso instrumento para ilustrar os argumentos naturais.

[4]

A - Se uma pessoa te liga pelo celular, deves atender?

$\mathrm{B}$ - Com certeza.

A - Mas te liguei milhares de vezes e nada.

B - Desculpa-me. Infelizmente, esqueci o celular em casa.

A - Ah, sim! A semana inteira?

Esse diálogo pode ilustrar propriedades de interface entre o argumento-tipo e o argumento-ocorrência ${ }^{10}$. "A" leva "B" a aceitar um modus ponens com um condicional genérico na primeira linha, e o enunciado que confirma o antecedente, na terceira, em $n$ ocorrências. $\mathrm{P} \rightarrow \mathrm{Q}, \mathrm{P}$, portanto $\mathrm{Q}$. Mas "B", mesmo assumindo o argumento, não teria tomado a decisão esperável (de atender " $A$ "). Diante de inúmeras chamadas de "A", "B" não as atende. Ele, contudo, argumenta, com desculpas, para tornar o fato mais razoável já que confessado. "Sem o telefone, não é possível atender, e eu o deixei em casa", diz ele, portanto, "infelizmente, não pude atender".

$\mathrm{O}$ argumento de "A" em [4] era crítico; o de "B", uma tentativa de anulá-lo. Mas a última linha é uma forma de ironia em que a desculpa de "B" se torna inverossímil. Ela implica que, se fosse verdade a justificativa, então ela seria válida para toda a semana, determinada, inferencialmente, por chamadas ao longo dos sete dias. Trata-se de um quadro argumentativo que simula uso prático de argumentos com ingredientes tais como: validade de modus ponens; condições de afetividade, como a ironia, por exemplo; o convite de "A" para que "B" seja racional diante da situação; o conhecimento enciclopédico de contex to de uso de celular; a resposta categórica de "B"; a hipérbole de "milhares"; a falsa confirmação de "ah, sim"; a crença de que "B" é falso em sua justificativa; as "desculpas" e o "infelizmente", apontando para um estado emocional de lamentação pelo ocorrido; a frustração revelada na forma de dizer "e nada".

Tal descrição de um argumento prático não é evidentemente precisa, podendo ser ampliada para situações mais complexas. Porém, algo parece certo, há uma racionalidade, ainda que complexa, que permite uma análise razoável, em que pesquisas

\footnotetext{
${ }^{9}$ Nesse caso, sinônimos.

${ }^{10}$ Argumento tipo: forma lógica do argumento; argumento ocorrência: uso do argumento.
} 
experimentais poderiam levar a conclusões de que o argumento de "A", se competindo com o de "B", é vencedor, por exemplo. A (tomada de) decisão de "B" de não seguir o primeiro argumento e a (tomada de) decisão crítica de " $A$ " parecem ser aceitáveis como verazes, ao passo que a justificativa de "B", não. Trata-se obviamente apenas de uma ilustração de interface com áreas cognitivas.

Além disso, inferências pragmáticas podem ser identificadas. Por exemplo, uma perspectiva griceana poderia ser invocada em nome de que a falsidade de ter dito que "milhares de chamadas foram realizadas" é uma maneira de levar à inferência de que foram muitas as tentativas, dentro de uma aparente violação da máxima de qualidade. De forma similar, dizer que esqueceu o telefone em casa, aparentemente uma desculpa desconectada do tópico, fica claramente justificado, dada a inferência de que "B" não estava em casa e não poderia atender, então, num exemplo de falsa quebra da máxima de relevância. Mas tal inferência pode ser cancelada por premissas adicionais, como "A - Mas você tem um celular e, nele, você poderia recuperar as minhas chamadas". De fato, o argumento dedutivo é, essencialmente, monotônico, mesmo com premissas adicionais; o argumento natural, ao contrário, pode ter sua conclusão alterada por uma premissa nova que se insere no conjunto das outras, caracterizando sua não monotonicidade. $\mathrm{O}$ exemplo a seguir ilustra o que se está dizendo, com um argumento dedutivo em comparação ao natural num diálogo:

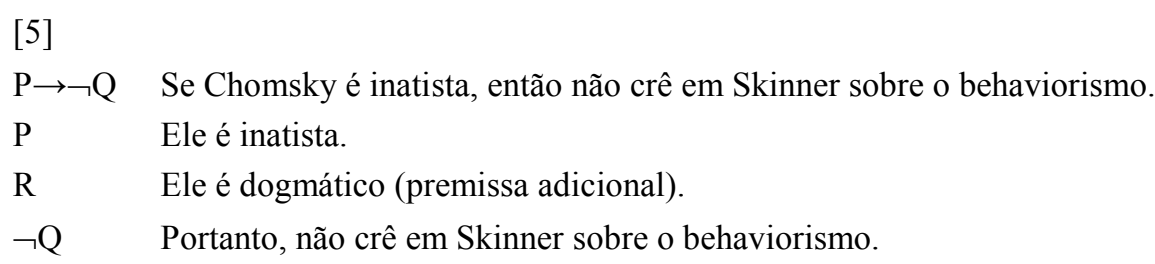

A conclusão se segue mesmo com a premissa adicional - monotonicidade -, porque o sistema é formal e a priori, normativo.

[6]

P A - Chomsky tem defendido, desde 1959, que há uma base inata.

$\mathrm{P} \rightarrow \mathrm{Q} \quad \mathrm{B}-\mathrm{Se}$ isso é assim, então ele crê na Gramática Universal desde essa época.

A - Eu não confio nas crenças dele (premissa adicional). ${ }^{11}$

B - Então não concluis que ele crê na Gramática Universal desde 1959.

A - Provavelmente não.

A conclusão é ameaçada pela premissa adicional, elemento afetivo - não monotonicidade -, porque não é normativo, nem a priori, mas exploratório ${ }^{12}$. A presença de uma premissa adicional, "Eu não confio nas crenças dele", introduz uma

\footnotetext{
${ }^{11}$ Esse diálogo, como um todo, representa um argumento prático. As duas primeiras linhas caracterizam uma estrutura modus ponens; as últimas três linhas, com a introdução da premissa adicional (ligada a condições de afetividade), entram em incoerência com a primeira parte do argumento.

${ }^{12} \mathrm{Ou}$ seja, com potencial relevante para pesquisa.
} 
condição afetiva que marca a não monotonicidade de o argumento prático ter a interferência em sua conclusão de elementos como a emoção. Ainda que isso pareça estranho, se não fosse assim, se a premissa em pauta parecesse impropriedade, como se justificaria que há uma aceitabilidade do argumento com ela. Pelo contrário, parece justo que se introduza a noção de condições afetivas, dado o fato de que elas estão presentes nos contextos de argumentação natural ou prática.

Uma outra fonte de condições de afetividade argumentativa são as chamadas expressões idiomáticas ou emocionais e seus efeitos sobre a argumentação. Algumas delas ilustram o conjunto de exclamações "que legal!", "que bom!", “que tristeza!", “tomara que consigas!", "boa sorte!", “te cuida!", “adorei!”, "vai dar tudo certo!”, "meu Deus!”, “ah, essa não!”, “bom te ver!”, “o prazer é meu!”, "seu malandro!”, “de jeito nenhum!"”.

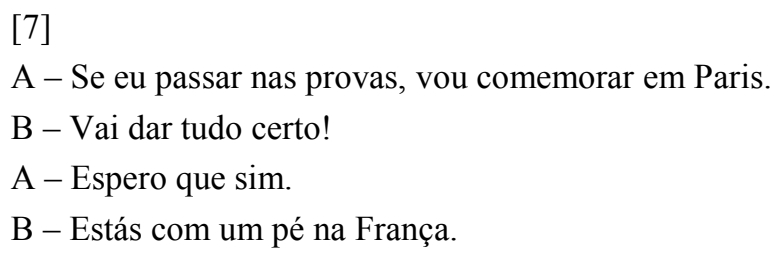

As condições de afetividade são positivas. "A" revela seu desejo num condicional, e "B" manifesta sua expectativa de estímulo com uma expressão idiomático-emocional "Vai dar tudo certo!" que carrega a inferência de que "B" está otimista e na expectativa de que "A" consiga o que quer. A forma do argumento é $\mathrm{P} \rightarrow \mathrm{Q}, \mathrm{P}$, portanto $\mathrm{Q}$, e o que "B" diz é que "A" vai passar nas provas e que vai comemorar em Paris, o que leva a inferir que o argumento é válido e correto.

[8]

A - Se você não cumprir a regra, você será preso.

B - Toda regra tem exceção.

A - Ah, não acredito!

B - Você verá!

O condicional inicial é a expectativa dialógica de que "B" o aceita, mas este contra-argumenta dizendo que toda regra tem exceção, o que leva a inferir que "B" não cumprirá, porque há exceções à regra e esta é uma delas - que afirma o antecedente, mas nega o consequente -, não indo, portanto, preso. A expressão afetiva de "A" é que " $\mathrm{B}$ " não conseguirá e será surpreendente se isso acontecer. " $\mathrm{B}$ " desafia e confirma que "A" constatará a veracidade do argumento de "B".

\section{CONSIDERAÇÕES CONCLUSIVAS}

Para ser fiel ao caráter exploratório do presente ensaio, trata-se de resumir em tópicos os itens que se destacam para a reflexão. Ao longo dos tempos, da cultura grega à cultura digital, o processo argumentativo tem sido considerado em suas propriedades formais e em suas propriedades dialógicas; tais propriedades podem ser desenhadas em 
interfaces comuns. Afinal de contas, não parece razoável excluir a Lógica Formal como disciplina icônica da racionalidade mais específica; sendo que, também, não parece plausível desconsiderarem-se as propriedades da racionalidade cotidiana, em nome de suas fragilidades. Seguem-se os tópicos. Eles representam um certo roteiro provocativo e exploratório no contexto das relações interdisciplinares entre Lógica e Comunicação, na iminência de um conceito mais complexo de racionalidade, que interage, naturalmente, com condições de afetividade, no uso de argumentos.

a) Desde Aristóteles, pode-se construir uma interface entre o argumento apodítico e o dialético; entre o formal e o comunicativo-social, em que se distingue uma concepção semântica de uma pragmática, entre esquema de validade e plausibilidade no uso de um argumento (ARISTÓTELES, 2010);

b) $\mathrm{O}$ argumento dedutivo, então, desenhado, formalmente, como normativo em sua validade ou não, pode também ser considerado no nível de um argumento natural, interagindo com inferências não monotônicas (HORN, 1972);

c) A perspectiva da conexão entre os dois tipos de contexto dos argumentos, enquanto formais e naturais, faz parte de uma perspectiva complementar de racionalidade stricto sensu e de racionalidade lato sensu em que esta inclui aquela; mais propriamente, há que se diferenciar a forma lógica, da forma do conteúdo, no uso do argumento (COSTA; STREY, 2014);

d) Nos argumentos práticos, o objeto em perspectiva é desenhado por propriedades heteromórficas, com inferências da vários tipos, requerendo investigação interdisciplinar (WALTON, 2012);

e) A conexão interdisciplinar de inferências pode ser considerada na aproximação entre condições de verdade e condições de afetividade (COSTA; STREY, 2014);

f) A linguagem natural, em seu uso dialógico, é o caminho para as interfaces do raciocínio argumentativo-dedutivo com o raciocínio prático (COSTA; STREY, 2014);

g) A argumentação dedutiva é uma abstração de $n$ situações de uso de argumentos, aquela que leva a conclusões necessárias; a argumentação prática é o uso dos argumentos, aquela que compreende conclusões não necessárias ou canceláveis (GRICE, 1989);

h) Emoção e razão interagem na perspectiva argumentativo-dialógica na linguagem natural (DAMASIO, 1994).

\section{REFERÊNCIAS}

ARISTÓTELES. Retórica. Trad. de Manuel Alexandre Jr., Paulo Farmhouse Alberto e Abel do Nascimento Pena. São Paulo: WMF Martins Fontes, 2012.

Órganon. Trad. de Edson Bini. 2. ed. São Paulo: Edipro, 2010.

AUSTIN, J. L. How to do things with words. New York: Oxford University, 1965.

COSTA, J. C.; STREY, C. Linguagem, argumentos e emoções. In: GERBASE, C. (Org.). Imaginação em rede: comunicação, memória e tecnologia. Porto Alegre: Sulinas, 2014.

Inferências linguísticas nas interfaces. Porto Alegre: EDIPUCRS, 2009.

DAMASIO, A. Descartes' error: Emotion, Reason, and the Human Brain. Nova York: G. P., 1994.

ELSTER, J. Alchemies of the mind: Rationality and the Emotions. Cambridge: Cambridge University, 1999. 
GRICE, H. P. Studies in the way of words. Boston: Harvard University, 1989.

HEIDEGGER, M. Platão: O sofista. Trad. De Marco Antônio Casanova. Rio de Janeiro: Forense Universitária, 2012.

HORN, L. R. On the Semantic Properties of Logical Operators in English. Ph.D. thesis, UCLA, Los Angeles, 1972.

JAKOBSON, R. Linguística e poética. In: e José Paulo Paes. São Paulo: Cultrix, 1987. Linguística e comunicação. Trad. de Izidoro Blikstein

LEMMON, E. J. Beginning logic. $2^{\text {nd }}$ ed. London: Chapman \& Hall, 1987.

MENDELSON, E. Introduction to Mathematical Logic. New York: D. Van Nostrand, 1987.

MOURA, H. M. M. Semântica e argumentação: diálogo com Oswald Ducrot. D.E.L.T.A., v. 14., n. 1, São Paulo, fev. 1998

PERELMAN, C.; OLBRECHTS-TYTECA, L. Tratado da argumentação - A nova retórica. Trad. de Maria E. G. G. Pereira. São Paulo: Martins Fontes, 1996.

SEARLE, J. R. Expression and meaning. Cambridge: Cambridge University, 1979.

SPERBER, D.; WILSON, D. Relevance: communication and cognition. $2^{\text {nd }}$ Ed. Oxford: Blackwell, 1986.

WALTON, D. Lógica informal. 2. ed. São Paulo: WMF Martins Fontes, 2012.

\section{Recebido em: 15/10/15. Aprovado em: 07/12/15.}

Title: Dialogue: practical argumentation and conditions of affectivity

Authors: Jorge Campos da Costa; Jonas Rodrigues Saraiva

Abstract: This essay is an attempt to an interdisciplinary approach to practical argumentative dialogue in its logic and affective dimension, from the perspective of a theoretical design in which reason and emotion coexist in a natural relationship between natural rationality and formal rationality. The assumptions are that dialogue is the locus classicus of practical reasoning in their linguistic-cognitive-communicative structure; that rationality, represented by deduction, stricto sensu, is the subject of a discipline, namely the Classical Logic; and that this discipline can be included in a lato sensu perspective of rationality, subject of an interdisciplinary approach in which coexist Logic, Linguistics, Cognitive Psychology, Communication Theory among others. Central to the research is the identification of inference in its various dimensions within the mentioned areas, the play of the language of the emotions, and their connections with the real conditions in the perspective of the validity and acceptability of arguments.

Keywords: Dialogue. Inference. Emotion. Argument.

Título: Diálogo: argumentación práctica y condiciones de afectividad Autores: Jorge Campos da Costa; Jonas Rodrigues Saraiva

Resumen: Este ensayo es un intento de enfoque interdisciplinario acerca del diálogo argumentativo práctico en su dimensión lógica y afectiva, desde la perspectiva de un diseño teórico en el que razón y emoción conviven en una relación entre racionalidad natural y racionalidad formal. Las hipótesis asumidas son las que el diálogo es el locus classicus de la argumentación práctica en su estructura lingüística-cognitivacomunicativa; que la racionalidad stricto sensu, representada por la deducibilidad, es objeto de una disciplina, a saber, la Lógica Clásica; y que esta disciplina puede ser incluida en una perspectiva de racionalidad lato sensu, objeto de una visión interdisciplinaria en la cual conviven Lógica, Lingüistica, Psicología Cognitiva, Teoría de la Comunicación, entre otros. Central para la investigación es la identificación de la inferencia en sus distintas dimensiones dentro de las áreas mencionadas, el juego del lenguaje de las emociones y sus conexiones con las condiciones reales en vista de la validez y aceptabilidad de los argumentos.

Palabras-clave: Diálogo. Inferencia. Emoción. Argumento. 